\title{
Is strategic asset management applicable to small and medium utilities?
}

\section{Helena Alegre}

Urban Water Division, Hydraulics and Environment Department, LNEC-National Laboratory of Civil Engineering, Lisboa, Portugal E-mail: halegre@lnec.pt

\begin{abstract}
Urban water infrastructures provide essential services to modern societies and represent a major portion of the value of municipal physical assets. Managing these assets rationally is therefore fundamental for the sustainability of the services and to the economy of societies. "Asset Management" (AM) is a modern term for an old practice - assets have always been managed. In recent years, significant evolution occurred in terms of the AM formal approaches, of the monitoring and decision support tools and of the implementation success cases. However, most tools developed are too sophisticated and data seek for small utilities. The European R\&D network COST Action C18 ( E-mail: www.costc18.org) identified key research problems related to the management of urban water infrastructures, currently not covered by on-going projects of the European Framework Program. The top 1 topic is "Efficient management of small community". This paper addresses challenges and opportunities for small and medium utilities with regard to infrastructure AM (IAM). To put this into context, the first sections discuss the need for IAM, highlight key recent developments, and present IAM drivers, as well as research and development gaps, priorities and products needed.
\end{abstract}

Keywords: small and medium utilities; strategic asset management; urban water systems 